\title{
Paraquat tongue
}

\section{Sapan Kumar ${ }^{1}$}

Published online: 20 July 2016

(C) Indian Society of Gastroenterology 2016

Paraquat or $N, N^{\prime}$-dimethyl-4, $4^{\prime}$-bipyridinium dichloride is a very common potent herbicide. Ingestion causes mucosal damage, gastrointestinal (GI) perforation, and renal and hepatic failure. In large quantity, it can even cause pulmonary, cardiac, and CNS toxicity $[1,2]$. A patient may complain of burning sensation of the mouth, nausea, yellowing of the eyes, breathing difficulty, decreased urine output, and erythematous tongue covered with necrotic sluff (Fig. 1). Ingestion of paraquat causes peroxidation of the lipid cell membrane and mitochondrial complex I (NADH-ubiquinone oxidoreductase) by free oxygen radical leading to apoptosis [2]. Current treatment is supportive and consists of gastric decontamination,

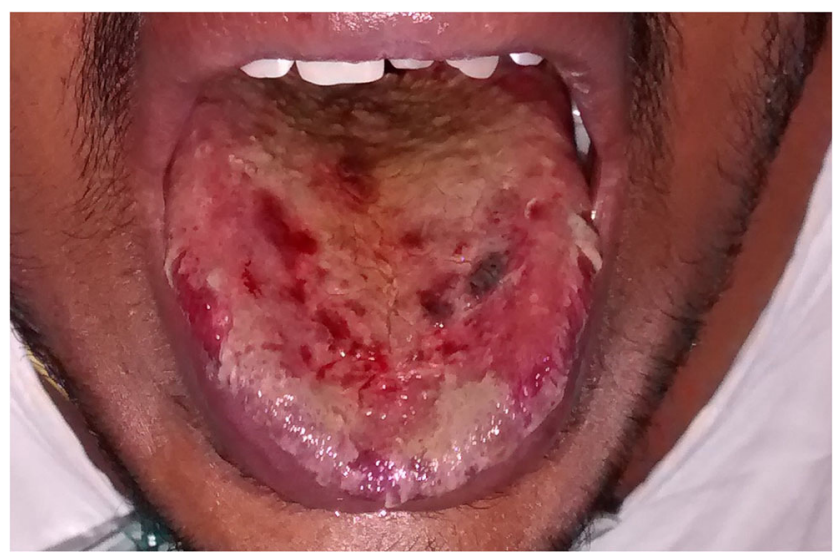

Fig. 1 In this patient, after 8 days of consumption of paraquat, the dorsum of the tongue is covered with yellow necrotic slough and ulceration with areas of active bleed and fissures over the anterior two-thirds of the tongue

Sapan Kumar

jupitersap@gmail.com

1 Department of Pulmonary Medicine, Christian Medical College and Hospital, Vellore 632 004, India steroids, and $\mathrm{N}$-acetyl cysteine as free radical scavenger. Hemoperfusion and hemodialysis is considered in patients with renal failure and pulmonary edema $[1,2]$. The presence of paraquat tongue should warrant a clinician to carefully look for GI perforation, mediastinitis, pneumothorax, and pneumomediastinum (Fig. 2). Early identification and treatment is important as paraquat has a very high mortality.

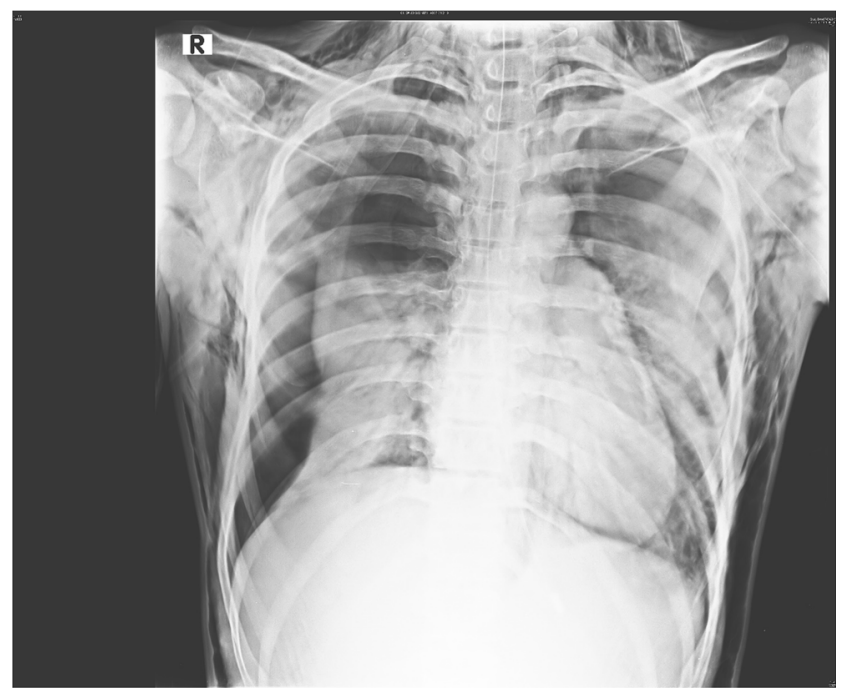

Fig. 2 Chest X-ray showing right-sided pneumothorax, paraquat induced lung disease, and extensive subcutaneous emphysema

\section{References}

1. Dinis-Oliveira RJ, Duarte JA, Sánchez-Navarro A, Remião F, Bastos ML, Carvalho F. Paraquat poisonings: mechanisms of lung toxicity, clinical features, and treatment. Crit Rev Toxicol. 2008;38:13-71.

2. Gawarammana IB, Buckley NA. Medical management of paraquat ingestion. Br J Clin Pharmacol. 2011;72:745-57. 